Psychiatric Bulletin

\title{
Consultant based services
}

\section{A discussion document}

\section{Introduction}

This discussion document has been produced by a Working Group of Council, which was asked to consider a consultant based model of psychiatric service provision. The Working Group met on three occasions, considered comments invited from Divisions, Sections and Regional Advisers and submitted by individual Fellows, and Members, reviewed the very limited literature' ${ }^{\prime}$ and considered different styles of practice in other parts of the world.

The concept of consultant based services has emerged in response to two different demands: to ensure that a greater proportion of treatment is provided by fully trained practitioners and to rectify the serious defects in the career structure of hospital doctors, particularly in the so-called acute specialties.

The Fourth Report from the Social Services Committee in 1981 (the Short Report) ${ }^{2}$ drew attention to both these issues and suggested that consultant numbers be doubled by 1995 , with the number of trainees being restricted to that required to fill consultant vacancies. These proposals were accepted by the Government but subsequently there was little impetus to implement them. No additional funding was made available and medical representative bodies expressed reservations about how such changes could be made.

In 1985 the Fifth Report from the Social Services Committee $^{3}$ urged the Government to take action and in 1986 a Special Committee on Manpower was established with representatives from the Joint Consultants' Committee and the DHSS. The result was the document Hospital Medical Staffing: Achieving a Balance. ${ }^{4}$

After consultation a further document Hospital Medical Staffing: Achieving a Balance-Plan for Action $^{5}$ was published in October 1987. This is not a consultative document but one for implementation with a mechanism for continuous review built in.

The principal proposals are:

(a) continuing consultant expansion at $2 \%$ per annum (psychiatry currently exceeds this);

(b) the adjustment of the number of career registrar posts to only that required to meet anticipated consultant vacancies: the JPAC mechanism to apply to registrars at a national and regional level; (c) the continuation of training opportunities for overseas graduates at registrar level: "visiting registrars", where numbers will be determined by the training posts available and the willingness of overseas graduates to train in this country for a four-year period;

(d) the conversion of superfluous training posts to new consultant posts, SHO posts and to nontraining 'service grade' posts. These last will be of two types: traditional clinical assistants, though no new posts in excess of five sessions will be created; and new 'service grade' posts, to a total number limited to $10 \%$ of the number of consultant posts, and subject to strict manpower controls on takeup and use, to provide for continuous work for contracted periods;

(e) the expectation that newly appointed consultants in the acute specialties will accept a greater degree of direct involvement in patient care;

(f) the provision of adequate support staffing in acute specialties to provide adequate 24 hour emergency cover (psychiatry is not listed as one of these specialties).

Plans for implementing these changes should be under way in 1988, though the changes are expected to take place over about a decade. The assumption is that as the numbers of consultants rise, and of registrars fall, more consultants on appointment will be expected to provide a service without regular trainees in the traditional model. These consultants will be asked to provide a consultant based service.

The remit of the Working Group was to consider how these manpower assumptions might affect the organisation and provision of psychiatric services. Whether the manpower assumptions themselves, generated primarily from the 'acute' specialties, are valid for psychiatry was not considered.

It is obvious that currently there are markedly different styles of provision and staffing levels in general psychiatry services throughout the country, dependent on historic, geographic and demographic factors and academic commitments, let alone the influence of individuals. The sub-specialties also vary markedly, dependent on whether acute in-patient care is provided. Some already provide consultant based services and some even provide consultant only services. 
Despite these differences it is felt that there are basic principles which ought to be borne in mind in discussion of a consultant based model of service.

\section{The nature of psychiatric practice}

It would be inappropriate to attempt a comprehensive statement of the nature of psychiatric practice. However, a number of important points need to be made.

There is much that is identical to the practice of all other medical specialties. A consultant not only has his clinical and managerial responsibilities but is required to teach, to undertake continuing education and to conduct research. Unless provision is made for these non-routine, non-clinical activities, and, above all, for 'thinking time', then advances in clinical care and in service delivery will become stunted. However, there are important differences which have to be acknowledged to ensure that there is a proper appreciation of the type and volume of work undertaken in psychiatric services.

The basis of all psychiatric assessment and treatment is listening to and talking to patients. This had traditionally been the role of the consultant and the trainee, though other disciplines now undertake such work. Psychiatry is, therefore, a manpower intensive specialty very sensitive to the number of staff employed. Watson ${ }^{6}$ argues that the only response to a reduction in the number of staff available for these activities would be to reduce the time spent with the individual patient, by seeing more in the same time. Standards of practice would quickly fall.

Many psychiatrists still have responsibilities to a substantial number of long-stay and highly dependent hospitalised patients, the chronic psychotic, psychogeriatic and the mentally handicapped. These patients need as much attention paid to their psychiatric needs as to their physical ones. Care in the community will move these patients to their district of origin but their disposal to smaller and scattered units in the NHS, or to local authority or private facilities, will increase the workload of the psychiatric services. The manpower effect of these changes has not been properly evaluated and is likely to be underestimated. The inadequacies of the Körner ${ }^{7}$ data set in this respect are already apparent.

Psychiatric services are organised on a district catchment area basis. The pressure of demand insists that there is a clear demarcation of the population to be served. However, Hirsch ${ }^{8}$, using Jarman scales, has shown a wide variation in admission rates between districts, probably a reflection of different levels of psychiatric morbidity and the style and extent of service provision.

It is remarkable that psychiatry was not immediately included on the list of 'acute specialties' requiring the 'safety net' provision. When all districts pro- vide a service to acute patients referred by a variety of agencies, in inner city areas many patients are first seen in casualty departments, self-referred, and as a result of the emphasis on treatment in the community most patients in acute units are now quite disturbed.

Comprehensive care in psychiatry is no longer seen as the exclusive preserve of the psychiatrists; other disciplines have emerged to form essential components of the multidisciplinary team. Difficulty in recruitment in these disciplines, which in some areas is considerable, markedly affects the demands on the psychiatric staff.

Multidisciplinary treatment is always time-consuming and the emphasis on treatment in the community involves the psychiatrist in much advisory, supervisory and liaison work with GPs and statutory and voluntary bodies. Such activities are difficult to quantify and are usually underestimated.

Consultant psychiatrists, exclusive amongst hospital specialists, act as responsible medical officer to patients detained under the Mental Health Act. As such they prepare reports on patients, e.g. for the consent to treatment procedure, the Mental Health Act Commission, and the hospital managers. They are also required to participate in mental health review tribunals. Forensic psychiatry is a regular part of the work of all consultant psychiatrists.

Despite the large amount of in-patient work, especially in busy acute units, there are no preregistration house officers in psychiatry. The routine service work in 'acute' specialties and out-of-hours duties performed by house officers is done by psychiatric SHOs and registrars.

\section{Definition of consultant based sevices}

A consultant based service is not a consultant only service; the distinction is vital.

In contemporary British psychiatry service delivery is by consultants, supported in the vast majority of cases by junior medical staff in training grades, usually from rotational training schemes, and permanent non-training junior staff, clinical assistants, and by the appropriate range of nursing and other professionals.

A consultant based service is one in which a consultant provides a comprehensive service to a defined group of patients supported by non-training medical staff and by the appropriate range of nursing and other professional personnel. Psychiatric trainees may be seconded for a period but are supernumerary with no specific service duties.

A consultant-only service is one in which a consultant without any supporting medical staff, though perhaps with supporting non-medical staff, provides for the entire psychiatric needs of a defined patient population.

A consultant-only service in general adult psychiatry could only provide current levels of care if 
huge numbers of consultants were to be appointed. Such consultants would no longer function as consultants within the Health Service have traditionally done, and, as such a service is not proposed in any of the relevant reports, we do not propose to consider it further.

A few districts which have experienced difficulties in recruiting junior medical staff in the training grades have set up a consultant based service in general adult psychiatry, most notably that described by Kingdon \& Szulecka.' This model has not proved economical in staff numbers or finance and has experienced difficulties even with enthusiastic consultants in post. It has not functioned with long-stay mental hospital beds nor with the pressures of an inner-city catchment area. There was an initial underestimate of consultant staff needed, then an urgent need to provide more supporting medical staff, then attempts to recruit post membership registrars and to reinstitute 'training' and to revert to more traditional ways of working.

Some consultant based services and consultantonly services already exist in sub-specialties which may function without in-patients, particularly child psychiatry and psychotherapy and, until recently, forensic psychiatry.

Experience is of long hours of work, concern about time for assessment of emergencies, prioritisation of cases and long waiting lists, heavy reliance on other professional and clerical staff, an emphasis on assessment rather than treatment, and shortage of time for administration, education and 'thinking'. Isolated and single-handed practice makes no provision for out-of-hours work, sickness or leave.

There is much to be learned from other countries but translation to this country requires judgement. In Europe there are many fewer general practitioners. Primary care and more specialist care is provided by a cadre of specialists who, although independent practitioners, may band together to produce a district-based specialist service. The number of specialists per head of population is very much higher than in the UK, especially in sub-specialties such as child and adolescent psychiatry. Administration and development is delegated to a chef de clinique who has reduced clinical role. Out-of-hours work and night cover is often provided by general medical trainees, many with no particular interest or skills in psychiatry.

\section{The duties and responsibilities of the consultant psychiatrist}

Again it would be too ambitious to attempt a comprehensive statement of the duties and responsibilities of a consultant psychiatrist. The following list in merely a guide to the breadth of duties undertaken.

\section{Clinical to patients}

to assess and treat psychiatric and physical illness in all settings in which patients may be found. to act as RMO.

to other medical to provide consulpractitioners tation and advice.

Administrative to participate in the consultation and management structures which provide the service to psychiatric patients.

Development to initiate and to participate in development of services.

Education to train junior medical staff. to train non-medical staff. to participate in continuous self education.

Research to conduct basic research as well as that related to service delivery.

\section{Conclusions}

Consultant based services are to be welcomed in the interests of improved treatment of patients and the correction of medical manpower imbalance. However, very careful thought will have to be given to each post proposed.

It is likely that a consultant based service will prove more expensive than the traditional model with trainees. A move to consultant based services is no solution to staffing and funding difficulties.

There are no good models of such a service in general psychiatry upon which to draw. Those which have been set up exist in atypical districts as a response to pre-existing difficulties.

Experience of consultant only services in the subspecialties, particularly in child psychiatry, while not an accurate paradigm, highlights the problems which could arise in inadequately staffed services.

The appearance of Achieving a Balance at the same time as Care in the Community offers the opportunity for improved treatment facilities for psychiatric patients in the future. However, both these major changes should be viewed as independently as possible to ensure that adequate provision of manpower is made under both proposals.

All the particular features of psychiatric practice already described must be acknowledged in the planning of a consultant based service. Current performance indicators measure predominantly hospital based activities performed during working hours, akin to other medical specialties. Essential extrahospital and liaison work and out-of-hours commitments intrinsic to good psychiatric practice 
are difficult to quantify and will be underestimated and even neglected unless care is taken.

Specific features such as the physical and psychiatric care of substantial numbers of long-stay patients must be adequately provided for. Future dispersal of these patients from hospital sites will increase the need for medical staff.

However, similarities between psychiatry and the other acute specialties must not be overlooked, for example, emergency referrals, casualty department work and an increasingly acutely ill in-patient population. The provisions of 'the safety net' should also apply to psychiatry.

Replacement of a registrar by a consultant is a complex matter and should not be by a simple translation of sessional commitment. The role of the consultant is much wider and if such an approach were adopted essential features of consultant practice would be overwhelmed by inappropriate service demand. On the other hand, a consultant may be a more efficient provider of service than a trainee.

There must be an acknowledgement of the dependence of psychiatrists on other disciplines in providing proper multidisciplinary treatment. Shortages and anticipated difficulty in recruitment in these disciplines must not be neglected in manpower calculations.

To provide a consultant based service a sufficiently large pool of consultants will be required to meet all the aspects of the workload, particularly regular outof-hours work and emergencies. Employing authorities will have to specify what arrangements will be made to cover for off-duty following onerous outof-hours work, sickness, leave and other unexpected circumstances. It should not be for overstretched consultants, with an already heavy face-to-face contact with patients, to cover for the similar workload of an absent consultant colleague.

\section{Recommendations}

There is no realistic case for a consultant only service. This would require a huge increase in consultant numbers. It would also require a prior and continuing increase in the number of trainees and would prove a very expensive form of service provision.

There must be an insistence on current minimum levels of consultant manpower as recommended by the Royal College of Psychiatrists before an attempt at implementation of a different style of service. Even the College minimum norms have not been met in numerous districts, in particular in the sub-specialties. College minimum norms themselves must not be used as the basis for calculation of possible consultant numbers in a consultant based service, and new norms will be required for such a service.

If a predominantly consultant based service is pro- posed, there is an urgent need to specify more clearly the duties and responsibilities of a consultant and the hours of work he or she is expected to perform. Without this, consultants with open-ended contracts will be very vulnerable to ever-increasing clinical demand.

Before any proposal of a consultant based service there must be a detailed and careful assessment of all the aspects of the work done by the existing service, by whom it is being done, and by whom it will be done under new arrangements. This emphasis on measuring work done and its appropriate allocation to staff of sufficient numbers and all grades is much preferable to simple sessional reallocation.

We estimate that to maintain current standards of practice a consultant based service will require twice the current College minimum norms, that is, 1 per 20,000 population in general adult psychiatry and 1 per 11,000 over the age of 65 years in psychogeriatrics. Figures for the sub-specialties are more difficult to estimate but are likely to be considerably in excess of current norms. With the changes proposed in Care in the Community, all these estimates could be considerably higher.

Because of the shortage of hard data, an experimental adequately funded consultant based service should be instituted in a typical district which has an existing service of high quality.

\section{References}

'Grasping the Nettle': the Report of the Collegiate Trainees' Working Party on Consultant Based Services, 1985-1986. Bulletin of the Royal College of Psychiatrists, 11, 68-70.

${ }^{2}$ DHSS (1981) Fourth Report from the Social Services Committee, 1980-1981 Session. London: HMSO.

3 - (1985) Fifth Report from the Social Services Committee, 1984-1985 Session. London HMSO.

${ }^{4}$ DHSS/JCC (1986) Hospital medical staffing: achieving a balance. British Medical Journal, 293, 147-151.

5_/- (1987) Hospital Medical Staffing: Achieving a Balance: Plan for Action London: DHSS

${ }^{6}$ Watson, J. P. (1985) Psychiatric manpower and the work of the consultant. Bulletin of the Royal College of Psychiatrists, 9, 170-173.

${ }^{7}$ WindsOR, P. (1986) Introducing Körner: A Critical Guide to the Work and Recommendations of the Steering Group on Health Services Information. Weybridge: The British Journal of Healthcare Computing (BJHC).

${ }^{8} \mathrm{HIRSCH}$, S. R. (1987) Planning for bed needs and resource requirements in acute psychiatry. Bulletin of the Royal College of Psychiatrists, 11, 398-407.

${ }^{9}$ KINGDON, D. G. \& SZULECKA, T. K. (1986) Establishing a district psychiatric service without psychiatric trainees. Bulletin of the Royal College of Psychiatrists, 10, 338340.

J. HigGINS

Chairman, Working Group on Consultant based Services

Approved by Council

March 1988 